Review Article

\title{
Use of Narrow-Diameter Implants in Completely Edentulous Patients as a Prosthetic Option: A Systematic Review of the Literature
}

\author{
S. Storelli $\mathbb{D},{ }^{1}$ A. Caputo $\mathbb{D},{ }^{2}$ G. Palandrani $\mathbb{D},{ }^{1}$ M. Peditto $\mathbb{D},{ }^{2}$ M. Del Fabbro $\mathbb{D},{ }^{1}$ \\ E. Romeo ${ }^{1}{ }^{1}$ and G. Oteri ${ }^{2}$ \\ ${ }^{1}$ Department of Biomedical, Surgical and Dental Sciences, University of Milan, Italy \\ ${ }^{2}$ Department of Biomedical and Dental Sciences and Morphofunctional Imaging, University of Messina, Italy
}

Correspondence should be addressed to M. Peditto; mpeditto@unime.it

Received 25 February 2021; Revised 15 May 2021; Accepted 10 June 2021; Published 22 June 2021

Academic Editor: Aritza Brizuela-Velasco

Copyright $\odot 2021$ S. Storelli et al. This is an open access article distributed under the Creative Commons Attribution License, which permits unrestricted use, distribution, and reproduction in any medium, provided the original work is properly cited.

\begin{abstract}
Objective. The objective of the present review is to assess the implant survival, marginal bone loss, and biomechanical features of narrow-diameter implants $(2.5-3.5 \mathrm{~mm})$ supporting or retaining full-arch fixed or removable restorations. Materials and Methods. Three operators screened the literature (PubMed, Cochrane Library, and Google Scholar) and performed a hand search on the main journals that focus on implantology until 24 March 2019. Only articles that considered full-arch restorations supported or retained by narrow-diameter implants $(2.5-3.5 \mathrm{~mm})$ were considered if they have a minimum of 10 patients and a mean follow-up of at least 6 months. The outcome variables were survival of implants and marginal bone loss. The review was performed according to the PRISMA statements. Risk of bias assessment was evaluated. Failure rates were analyzed using random effect Poisson regression models to obtain the summary estimate of 5-year survival rate and marginal bone loss. Results. A total of nine papers were finally selected, reporting a high survival rate of the implants. Eight studies focused only on the mandible while one study reported data from both mandible and maxilla. All studies reported on removable restorations; none focused on fixed rehabilitations. The estimated survival rate for 5 years of follow-up was calculated to be $92.25 \%$ for the implants. The estimated marginal bone loss after 5 years was calculated to be $1.40 \mathrm{~mm}$. No study reported implant fractures. Conclusions. With the limitations of the present study, there is evidence that $2.5-3.5 \mathrm{~mm}$ narrow-diameter implants retaining a removable restoration can be a successful treatment in fully edentulous patients. No data on fixed restorations was available.
\end{abstract}

\section{Introduction}

Complete edentulism significantly reduces masticatory function, and it is a significant oral health issue concerning a large part of the adult population [1].

Following tooth extraction, a process of residual ridge resorption (RRR) begins, and it is most intense during the first year, when approximately $60 \%$ of the alveolar ridge is resorbed and is directly related to the duration of edentulism [2-4].

Human reentry studies showed horizontal bone loss of $29-63 \%$ and vertical bone loss of $11-22 \%$ after 6 months following tooth extraction [5].
However, the bone resorption activity continues slowly throughout life, resulting in the loss of a large amount of jawbone structure [6].

Residual ridge resorption (RRR) is a common problem, and it represents a chronic, progressive, irreversible, and disabling disease, probably of multifactorial origin [6].

Most resorption occurs in the alveolar process, whereas the basal portion remains relatively intact but only decreases bone density due to reduced function [6].

The edentulous arch is a vital structure present during the entire life of the patient, regardless of tooth presence or function [7]. All this often leads to a situation where there is not 
sufficient support for the appropriate function of the removable complete denture.

Conventional dentures represent a noninvasive option for the treatment of complete edentulism and avoid a surgical procedure for the patient. However, in a large number of cases, this rehabilitation does not satisfy the patients' expectations, as many complaints are reported primarily related to functionality and adaptation [8].

On the contrary, the attachment of removable dentures to osseointegrated dental implants brings considerable benefits, including the increase of denture stability, functional efficiency, and comfort. For these reasons, the implantsupported overdenture has become a common clinical practice, and to date, a two-implant overdenture is considered the first choice for the treatment of the fully edentulous mandible $[9,10]$.

However, in some cases, the inevitable resorption of the alveolar ridges after tooth extraction can make the placement of standard-diameter implants $(>3.5 \mathrm{~mm})$ difficult or even impossible without the use of more advanced bone regenerative procedures.

The use of standard-diameter implants in narrow alveolar ridges may lead to thin buccal or lingual bone or even large dehiscences, increasing the risk of complication and failure $[11,12]$.

In addition, elderly patients and, especially, patients with comorbidities are often unwilling to undergo extensive surgical procedures such as bone regeneration in order to receive standard-diameter implants [13]. Adapting dimensions of dental implants allows simpler surgical procedures.

In many cases, the interforaminal height can be reduced to $<10 \mathrm{~mm}$ (Class D or E according to Lekholm and Zarb or Class IV according to the classification system for edentulous patients of the American College of Prosthodontics) [14, 15].

This situation represents the most complex to rehabilitate.

NDIs (narrow-diameter implants) $10 \mathrm{~mm}$ long may be too long for them, while short, wide implants may be too wide for thin residual ridges [16].

Such patients represent the most complex and high-risk treatment situation. MDIs $10 \mathrm{~mm}$ long may be too long for them, whereas short and wide implants may be too wide for slim residual ridges $[17,18]$.

To date, there are few studies in the literature on the use of short implants for the rehabilitation of edentulous arches.

In the case of a narrow ridge, two options are available. The first option is to place a standard-diameter implant secondly to bone augmentation procedures [11]; the second option is to use a narrow-diameter implant (NDI $<3.5 \mathrm{~mm})$ [11].

Although widely validated in literature, bone augmentation procedures are much more invasive and may have a higher risk of complications than conventional placement of implants.

Narrow-diameter implants (NDIs) have been introduced as an alternative treatment option in single-tooth gaps or edentulous ridges with limited width $[19,20]$.

The reduced-diameter implant classification was updated in 2018 (Table 1) [21].
TABLE 1: Reduced-diameter implant classification.

\begin{tabular}{lc}
\hline Category & Diameter \\
\hline 1 & $<2.5$ (mini-implants) \\
2 & $2.5 \mathrm{~mm}$ to $<3.3 \mathrm{~mm}$ \\
3 & $3 \mathrm{~mm}$ to $3.5 \mathrm{~mm}$ \\
\hline
\end{tabular}

The advantages of NDIs include the following: (1) no bone grafting, (2) reduced bleeding, (3) minimal postoperative discomfort, (4) lower costs for the patients, and (5) faster healing time $[21,22]$.

However, NDIs also present some disadvantages: (1) reduced bone-to-implant contact (BIC) and osseointegration [20], (2) increased risk of implant fracture due to reduced mechanical properties, and (3) increased risk of implant overloading.

However, it is recommended that NDIs are used with caution. The reduction in implant diameter reduces the contact surface between bone and implant, thus increasing the risk of fracture due to reduced mechanical stability [23].

Many publications demonstrate the risk of "fatigue" fracture of small-diameter implants [20, 24].

The neck of the implant represents a potential fracture zone when subjected to high bending force. Due to these mechanical limitations, the NDIs are only recommended to increase retention and stability of mandibular overdenture in cases of limited bone thickness [25, 26].

To reduce this risk, new alloys have been introduced.

Preliminary results obtained in one study showed that reduced-diameter implants with a titanium-zirconium alloy can withstand masticatory forces in total rehabilitations [11].

The present review has the primary objective to evaluate the survival rate, the marginal bone loss (MBL), and biomechanical features of NDIs of 2.5 to $3.5 \mathrm{~mm}$ of diameter (categories 2 and 3) [21] used in the treatment of completely edentulous patients through full-arch removable or fixed restorations.

\section{Materials and Methods}

This systematic review was written according to the guidelines indicated by the "PRISMA statement" and by the Cochrane Handbook for Systematic Reviews of Interventions (version 5.1.0).

The focused question was "What is the survival rate of narrow-diameter implants $(2.5-3.5 \mathrm{~mm})$ supporting removable or fixed restorations in fully edentulous patients?" A preliminary PICOS assessment was used to define the search strategy with the following criteria.

2.1. Participants. The participants are edentulous patients (both jaws or either upper or lower jaw) with a full-arch implant-retained fixed or removable prosthesis.

2.2. Interventions. The interventions are full-arch fixed or removable overdenture prosthesis supported by narrowdiameter implants (2.5 to $3.5 \mathrm{~mm})$.

\subsection{Outcome Measures}


(i) Implant survival rate

(ii) Prosthesis survival rate

(iii) Marginal bone loss

Other variables were searched and described when present: biomechanical features, prosthesis survival, prosthetic complications, reconstruction material, and implant system used.

2.4. Types of Studies. The types of studies are randomized controlled trials (RCTs) and prospective and retrospective clinical trials (case-control studies, cohort studies, and case series). Studies had to report data on a minimum of 10 participants and have a minimum of 6 months of follow-up.

2.5. Search Strategy. Three investigators conducted an independent electronic search of the English literature (AC, GP, and SS), using PubMed, Cochrane Library, and Google Scholar for studies published until March 2019, including the following search strategy (MeSH and free terms) for each database (Figure 1):

(i) (edentulous) AND $((((((($ small diameter implant) OR small-diameter implant) OR narrow implant) OR mini-implant) OR mini implant) OR transitional implant) OR temporary implant) OR provisional implant): 830 hits

(ii) (Edentulous) AND (small diameter implant OR small-diameter implant OR narrow implant OR mini-implant OR mini implant OR transitional implant OR temporary implant OR provisional implant)": 178 hits

(iii) ("edentulous") AND ("small diameter implant" OR small-diameter implant OR narrow implant OR mini-implant OR “mini implant” OR transitional implant OR temporary implant OR provisional implant): 1230 hits

Moreover, the issues from January 2016 to March 2019 of the following journals were hand-searched: Clinical Oral Implants Research, International Journal of Periodontics and Restorative Dentistry, Journal of Periodontology, Journal of Clinical Periodontology, International Journal of Oral and Maxillofacial Implants, Journal of Prosthetic Dentistry, Journal of Prosthodontics, and Journal of Oral Rehabilitations.

Moreover, the bibliographies of previous systematic reviews on the topic as well as selected articles were thoroughly screened.

\subsection{Inclusion Criteria}

(i) Studies published in English

(ii) Human studies

(iii) Sample size $\geq 10$ patients (iv) Studies conducted on completely edentulous patients rehabilitated with small-diameter implants (2.5-3.5 mm)

(v) Full-arch removable or fixed full-arch restorations

(vi) Follow-up times greater than six months

(vii) Prospective cohort studies, randomized controlled or nonrandomized controlled trial, retrospective case-control or "single cohort" studies, and case series

\subsection{Exclusion Criteria}

(i) Studies reporting data of the same cohort of patients, with different follow-ups

(ii) Case reports on animal or in vitro models

2.8. Study Selection. All retrieved articles were screened for duplicates by two reviewers (GP-AC). Titles and abstracts were then independently screened by the same review authors (GP-AC). Articles meeting the inclusion criteria and those whose abstract presented unclear data were collected as full text. The papers were then assessed by three authors (GP-AC-MP) that defined if the articles were to be included or not. Any disagreement was resolved by discussion with the other reviewers (SS-GO).

2.9. Data Extraction. Data were extracted by three reviewers (AC-GP-MP) using data collection forms [27].

Study design, implant manufacturer, and data on restorations were extracted. The survival rates of implant and prosthesis were extracted. Implant survival was considered if the implant was present at the follow-up examination. Moreover, when reported, data on marginal bone loss and patient satisfaction was also extracted. When the reported data were unclear, authors contacted by emails the corresponding authors and asked for more information.

2.10. Risk of Bias Assessment. The risk of bias assessment for the included studies was performed independently by two reviewers (GP and AC) using The Cochrane Collaboration's tool for assessing the risk of bias including the following domains: allocation concealment, random sequence generation, blinding of participants and personnel, blinding of outcome assessment, incomplete outcome data, selective reporting, and other bias.

The assessment was not centered on the outcomes of the paper but the ones of the present review.

Each domain was considered at low, unclear, or high risk of bias agreeing to the evaluation criteria as reported in the Cochrane Handbook for Systematic Reviews of Interventions version 5.1.0.

After judgment was given for each of the domains mentioned above, studies were divided into the following groups: studies with low risk of bias, if all domains were considered at low risk of bias; unclear risk of bias, if one or more domains were considered at unclear risk of bias; and high risk of bias, 


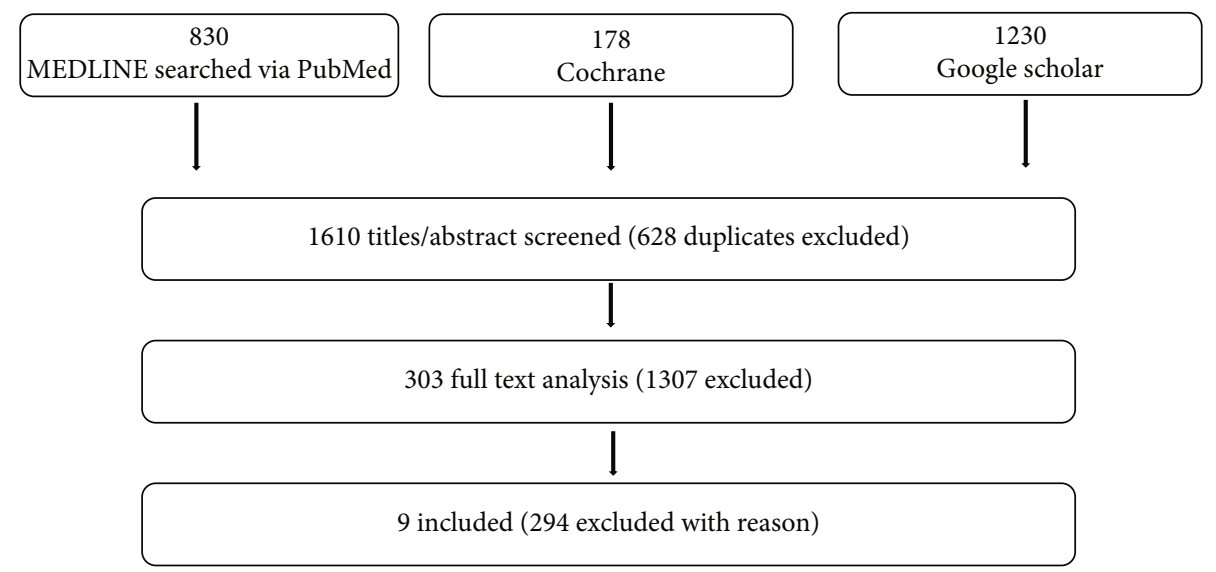

FIGURE 1

if one or more domains were reported at high risk of bias. Cases of disagreement were resolved by discussion.

2.11. Statistical Analysis. The mean follow-up duration was directly extracted by the articles, provided by adjunctive information by the authors or estimated from the original data. For further analysis, the total number of events was considered to be Poisson distributed for a given sum of implant exposure years, and five-year survival and success rates for implants and prosthesis were estimated considering a Poisson distribution [27, 28]. Data were tabulated and analyzed using the software Microsoft Excel 2016 (2016 Microsoft Corporation, Santa Rosa, CA, USA) and the software GraphPad Prism 5.0 (GraphPad, San Diego, CA, USA). For the data synthesis, weighted mean values, median, $95 \%$ confidence intervals, and ranges were used. Distribution of implant failures was assessed using a time-to-event analysis. Studies that did not provide information regarding the timing of implant loss were excluded from the analysis. Life table analysis and Kaplan-Meier analysis were used to estimate the cumulative implant survival rate. The cumulative survival rates of implants with diameter 2.5 to $3.3 \mathrm{~mm}$ and 3.3 to $3.5 \mathrm{~mm}$ were compared using the log-rank (Mantel-Cox) test. The significance threshold was set at $p=0.05$. For each study, the estimated MBL at five years was calculated by dividing the MBL reported by years of follow-up and multiplying for five, assuming a constant marginal bone loss over time [27]. All analyses were performed using IBM SPSS Statistics (IBM Corporation, Armonk, NY).

\section{Results}

The electronic search identified a total of 2238 (830 MEDLINE, 178 Cochrane database, and 1230 Google Scholar) (Table 2).

The manual research did not produce any additional article. After removing duplicate papers, a total of 1610 were screened. A total of 303 papers underwent full-text analysis. After full-text reading, 294 papers were excluded. Reasons for exclusion are listed in Table 3.

Any disagreement was resolved by discussion. When, after discussion, there was still doubt, authors were contacted by email and asked for better explanations. Finally, nine papers were included. Therefore, nine studies were actually selected and included in the review (Figure 1).

3.1. Excluded Studies. Each full text was read, and the reason for exclusion is reported in Table 3. Out of 294 excluded papers, 183 reported on implants with diameter $>3.5 \mathrm{~mm}$ or $<2.5 \mathrm{~mm}, 55$ had a pool of implants with mixed diameter, 9 reported nonhuman studies, 11 reported on rehabilitations with bone regenerations, 21 analyzed partially edentulous patients, 6 reported data with follow-up less than 6 months, 3 reported data on the same pool of patients (a third one was included), 1 was a review, 4 were studies in languages other than English, and 1 reported a pool of patients less than 10 .

3.2. Study Characteristics. Finally, a total of 9 papers [29-37] were included in the qualitative analysis. Descriptive data regarding the characteristics of included studies are reported in Table 4 . Four RCTs and 4 prospective studies and 1 retrospective study were selected (Table 4).

3.3. Risk of Bias. The risk of bias summary is presented in Table 5. Among the studies, 4 were classified as high risk of bias $[29,34,36,37]$ and 5 were classified as unclear risk of bias $[30-33,35]$.

3.4. Data Analysis. The included studies were four randomized controlled trials [30, 32, 33, 35], four prospective studies $[29,31,34,37]$, and 1 retrospective study [36]. All studies reported cases of fully edentulous patients and implant placement with narrow-diameter implants $(\varnothing 2.5-3.5 \mathrm{~mm})$. Eight studies investigated only the edentulous mandible and 1 investigated both maxilla and mandible (Table 4). A total of 885 NDIs ( $\varnothing 2.5-3.5 \mathrm{~mm}$ ) in 398 patients were followed for at least six months (range 6-91). Implant diameter, implant length, and implant system are shown in Table 4. All included studies reported data on removable overdentures. No data was found on fixed restorations supported by NDI in completed edentulous patients. Five studies used flap reflection techniques for implant placement [31-33, 36, 37], three studies used a flapless technique [29, 30, 34], and, in the remaining study, the technique was not specified [34] 
TABLE 2: Search strategy used and hits for each searched database.

\begin{tabular}{|c|c|c|}
\hline Database of published studies & Search strategy used & Hits \\
\hline $\begin{array}{l}\text { MEDLINE searched via PubMed searched } \\
\text { on March 24, } 2019\end{array}$ & $\begin{array}{c}\text { (edentulous) AND }(((((((\text { small diameter implant) OR small-diameter implant) } \\
\text { OR narrow implant) OR mini-implant) OR mini implant) OR transitional } \\
\text { implant) OR temporary implant) OR provisional implant })\end{array}$ & 830 \\
\hline $\begin{array}{l}\text { Cochrane Central Register of Controlled } \\
\text { Trials searched on March 20, } 2019\end{array}$ & $\begin{array}{l}\text { (edentulous) AND (small diameter implant OR small-diameter implant } \\
\text { OR narrow implant OR mini-implant OR mini implant OR transitional } \\
\text { implant OR temporary implant OR provisional implant) }\end{array}$ & 178 \\
\hline $\begin{array}{l}\text { Google Scholar searched on March 23, 2019, } \\
\text { via http://www.scholar.google.com/ }\end{array}$ & $\begin{array}{l}\text { (“edentulous") AND (“small diameter implant” OR small-diameter implant } \\
\text { OR narrow implant OR mini-implant OR "mini implant" OR transitional } \\
\text { implant OR temporary implant OR provisional implant) }\end{array}$ & 1230 \\
\hline
\end{tabular}

TABLE 3: Excluded papers with reasons.

\begin{tabular}{lc}
\hline Reason of exclusion & $\begin{array}{c}\text { Number of excluded } \\
\text { studies }\end{array}$ \\
\hline Mean follow-up $<6$ months & 6 \\
Mixed diameter & 55 \\
Partially edentulous & 21 \\
Out of topic (diameter $>3.5 \mathrm{~mm}$ or $<$ & 183 \\
$2.5 \mathrm{~mm}$ ) & 11 \\
Bone regeneration & 3 \\
Same pool of patients of another article & 1 \\
Number of patients $<10$ & 9 \\
Nonhuman study & 1 \\
Review & 4 \\
Language & \\
\hline
\end{tabular}

(Table 4). All the studies reported the implant survival rate with a range from $83.3 \%$ to $100 \%$; only three studies reported the implant success rate with a range from $51.3 \%$ to $94 \%$. The estimated survival rate after five years (\%) derived from Poisson regression analysis varied between $81.7 \%$ and $100 \%$ (Table 6).

After normalization of the results, the weighted mean was $96.75 \%$ with a median of $98.35 \%$ and a $95 \%$ CI of $90.87 \%$ to $100 \%$. The life table analysis showed results of up to 10 years of follow-up for a minimum number of implants, with a cumulative 10 years of follow-up of 95.85 (Table 7).

The Kaplan-Meier analysis was divided by diameter range into two groups $2.5-3.25 \mathrm{~mm}$ and $3.3-3.5 \mathrm{~mm}$. The curves have been compared using the log-rank (MantelCox) test. There is a significant difference $(p=0.01)$, due to a greater number of early events (implant losses) in the group of implants with 2.5 to $3.25 \mathrm{~mm}$ diameter. The main contribution comes from the study by Marcello-Machado et al., in which there were 10 failures (out of 17 in this group) in the first year (4 within 2 months, 1 at $3 \mathrm{~m}, 3$ at $4 \mathrm{~m}, 1$ at 5 $\mathrm{m}$, and 1 at $7 \mathrm{~m}$ ) (Figure 2).

One implant failed in each test group in two articles [29, 31], six implants in Morneburg's study, and three implants in Muller's due to peri-implant infection. Ma et al. reported that 17 implants failed without explaining the reasons for failure. Marcello-Machado reported 10 implants lost out of 60 in the first year, thus leading to a very high failure rate over the first year. No one-piece to two-piece implant fractures occurred in the reviewed articles. All nine studies reported the bone level changes at the end of each follow-up from 6 months to 7.6 years. The MBL (marginal bone loss) reported in the nine studies ranged from $0 \mathrm{~mm}$ to $2.82 \mathrm{~mm}$, and the mean MBL estimated after five years was $1.40 \mathrm{~mm}$ with a median of $1.24 \mathrm{~mm}$ and a $95 \%$ CI of 0.55 to $2.03 \mathrm{~mm}$ (Table 6). All the papers reported implant loading time: four studies followed conventional loading, after 3 months from implant placement [31, 33, 34, 37]; three studies followed early loading protocols, from 1 to 3 months from implant placement $[32,35,36]$; and one article followed immediate loading, within 7 days from implant placement [30]. Only one article followed both immediate and conventional loading [29] (Table 4). About the prosthetic rehabilitation, all patients were restored with removable overdentures. In all the studies, either a ball or a locator attachment was used; only in one study was a bar considered [33]. Seven studies described mandibular overdentures supported either by two implants [29-32, 34-37], by four implants, or by three implants [31], while only one of the included studies evaluated maxillary overdentures supported by three or four implants [33] (Table 4). The interforaminal area was preferred for implant placement in the mandible. In the maxilla, implant positions were not described. A prosthesis was considered to have survived whenever, although some modification during the observation time was made, the rehabilitation was still in situ at the end of the observation period [27]. Only four studies reported data about prosthesis survival: three studies reported survival of $100 \%$ after six months, two years, and three years, respectively $[31,32,36]$ and one of $85 \%$ after one year [30]. The most frequent prosthetic complications were healing abutment loosening, loosening of the locator/ball attachment, and replacement of retentive cap. The fracture of mandibular overdentures was found in six cases at one year [29] and twenty-seven cases at ten years [33]. Only two studies assessed the patient's satisfaction with the overdenture by validated questionnaires based on a visual analog scale (VAS) at one year and six months, respectively [30, 32]. In these questionnaires, patients indicate their satisfaction with a crossed mark on a scale from 0 to 100 (from not at all satisfied to extremely satisfied). In both studies, the overall patient satisfaction with the overdenture was high (score $>60)$. The 


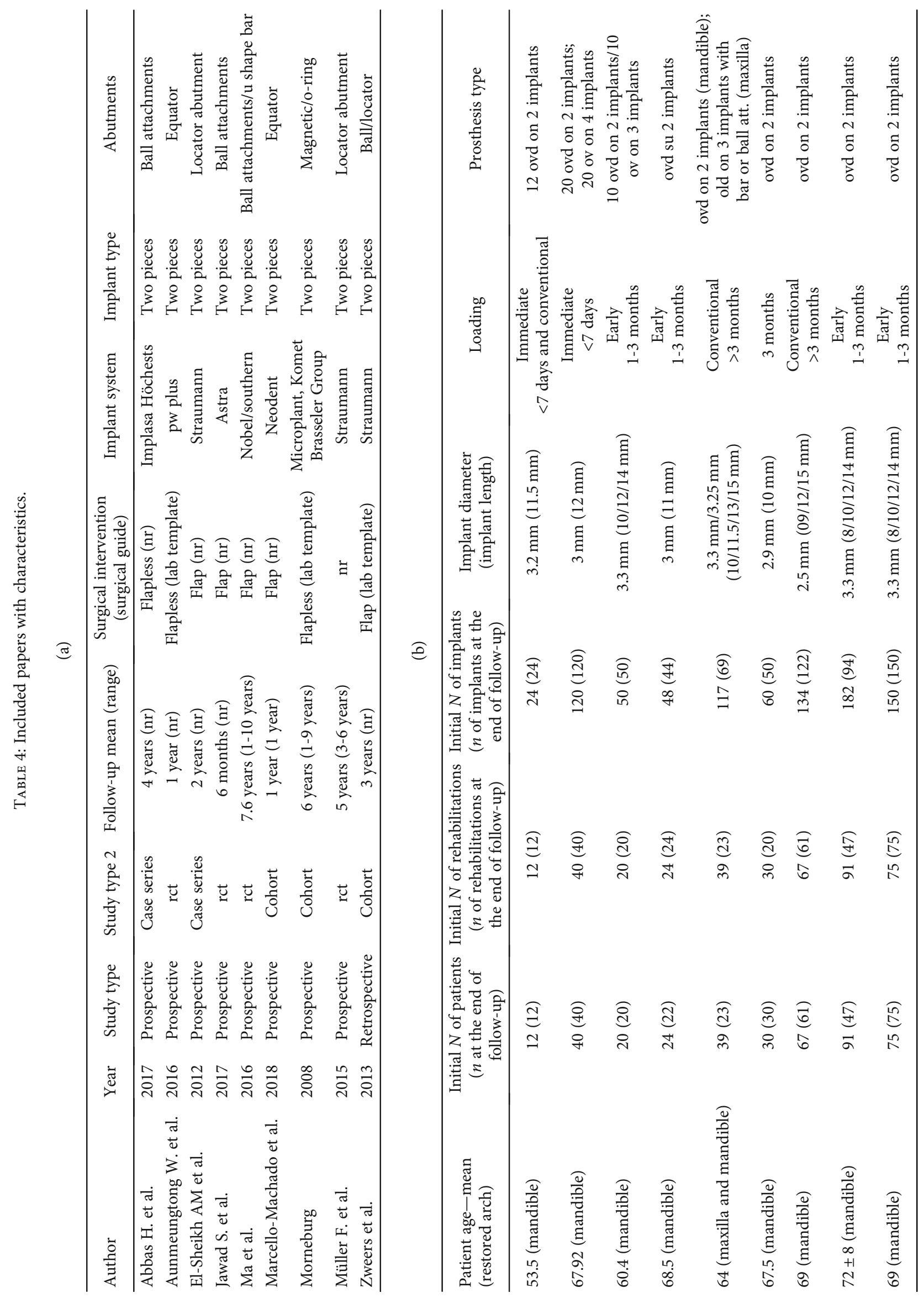


TABLE 5: Risk of bias.

\begin{tabular}{|c|c|c|c|c|c|c|c|c|}
\hline Author & Design & $\begin{array}{c}\text { Random } \\
\text { sequence } \\
\text { generation }\end{array}$ & $\begin{array}{c}\text { Allocation } \\
\text { concealment }\end{array}$ & $\begin{array}{c}\text { Blinding of } \\
\text { participants and } \\
\text { personnel }\end{array}$ & $\begin{array}{l}\text { Blinding of } \\
\text { outcome } \\
\text { assessment }\end{array}$ & $\begin{array}{l}\text { Incomplete } \\
\text { outcome } \\
\text { data }\end{array}$ & $\begin{array}{l}\text { Selective } \\
\text { reporting }\end{array}$ & $\begin{array}{l}\text { Other } \\
\text { bias }\end{array}$ \\
\hline Abbas H. et al. & $\begin{array}{l}\text { Prospective } \\
\text { Case series }\end{array}$ & - & - & - & - & & & \\
\hline $\begin{array}{l}\text { Aunmeungtong } \\
\text { W. et al. }\end{array}$ & $\begin{array}{c}\text { Prospective } \\
\text { RCT }\end{array}$ & & & & & & & \\
\hline $\begin{array}{l}\text { El-Sheikh AM } \\
\text { et al. }\end{array}$ & Prospective & & & & & & & \\
\hline Jawad S. et al. & $\begin{array}{c}\text { Prospective } \\
\text { RCT }\end{array}$ & & & & & & & \\
\hline Ma et al. a-b & $\begin{array}{c}\text { Prospective } \\
\text { RCT }\end{array}$ & & & $=$ & $=$ & & & \\
\hline $\begin{array}{l}\text { Marcello- } \\
\text { Machado et al. }\end{array}$ & Prospective & $=$ & $=$ & $=$ & $=$ & & & \\
\hline Morneburg & $\begin{array}{l}\text { Retrospective } \\
\text { Cohort }\end{array}$ & $=$ & - & - & - & & & \\
\hline Müller F. et al. & $\begin{array}{c}\text { Prospective } \\
\text { RCT }\end{array}$ & & & 7 & 0 & & & \\
\hline Zweers et al. & $\begin{array}{c}\text { Retrospective } \\
\text { Cohort }\end{array}$ & $=$ & - & $=$ & - & & & \\
\hline
\end{tabular}

ability to speak, the level of comfort, the stability of the dentures, perception of the chewing ability, and function showed similar improvement in both studies pre- and postimplant placement. In particular, in Aunmeungton's study, the average patient satisfaction in Groups 1 (two narrow implants $\varnothing 3$ $\mathrm{mm}$ ), 2 (four narrow implant $\varnothing 3 \mathrm{~mm}$ ), and 3 (standard implant $\varnothing 3.5 \mathrm{~mm}$ ) was $67.83 \pm 5.26,70.88 \pm 4.12$, and 60.85 \pm 8.54 , respectively. There were no significant differences in patient satisfaction between Groups 1 and 2. However, patient satisfaction in these two groups was statistically higher than Group 3.

\section{Discussion}

Up to date, only a few comparative prospective clinical studies are available to document survival or success rates of NDI.
Therefore, the authors decided to also include observational studies in this review.

The quality and level of evidence were limited in general with a high risk of bias, so the interpretation of this data requires caution.

It is interesting to note that all included studies were describing overdenture rehabilitations while no studies were found concerning full-arch restorations supported by NDI.

Only two papers compared narrow with standard implants. Augmentonn compared three groups, in Groups 1 and 2, two and four minidental implants, respectively, were placed and immediately loaded by overdentures, using Equator $^{\mathrm{VR}}$ attachments. In Group 3, conventional implants were placed. After osseointegration, the implants were loaded by overdentures, using ball attachments.

There was no significant difference $(p<0.05)$ in clinical results regarding the number (two or four) of minidental 
TABLE 6: Estimated implant survival rate and MBL at 5 years for the included studies.

\begin{tabular}{|c|c|c|c|c|c|}
\hline Author & $\begin{array}{l}\text { Implant survival } \\
\text { rate reported }\end{array}$ & $\begin{array}{c}\text { Estimated survival rate } \\
\text { at } 5 \text { years }(\%)\end{array}$ & $\begin{array}{l}\text { MBL } \\
\text { reported }\end{array}$ & $\begin{array}{c}\text { Estimated mean MBL } \\
\text { at } 5 \text { years }\end{array}$ & $\begin{array}{l}\text { Prosthesis } \\
\text { survival rate }\end{array}$ \\
\hline Abbas H. et al. & $95.8 \%$ & $94.8 \%$ & $1.25 \mathrm{~mm}$ & $1.56 \mathrm{~mm}$ & NR \\
\hline Aunmeungtong $\mathrm{W}$. et al. & $100 \%$ & $100 \%$ & $0.56 \mathrm{~mm}$ & $2.82 \mathrm{~mm}$ & NR \\
\hline El-Sheikh AM et al. & $100 \%$ & $100 \%$ & $0.8 \mathrm{~mm}$ & $2 \mathrm{~mm}$ & $100 \%$ \\
\hline Jawad S. et al. & $100 \%$ & $100 \%$ & NR & NR & $100 \%$ \\
\hline Ma et al. & $84.7 \%$ & $89.88 \%$ & $2.45 \mathrm{~mm}$ & $1.61 \mathrm{~mm}$ & NR \\
\hline Marcello-Machado et al. & $83.3 \%$ & $81.7 \%$ & $0 \mathrm{~mm}$ & $0 \mathrm{~mm}$ & $\mathrm{Nr}$ \\
\hline Morneburg & $95.5 \%$ & $96.27 \%$ & $1.1 \mathrm{~mm}$ & $0.92 \mathrm{~mm}$ & NR \\
\hline Müller F. et al. & $98.35 \%$ & $98.35 \%$ & $0.6 \mathrm{~mm}$ & $0.6 \mathrm{~mm}$ & NR \\
\hline \multirow[t]{2}{*}{ Zweers et al. } & $100 \%$ & $100 \%$ & $0.48 \mathrm{~mm}$ & $0.8 \mathrm{~mm}$ & $100 \%$ \\
\hline & & $\begin{array}{c}\text { Estimated cumulative survival } \\
\text { rate at } 5 \text { years }(\%) \\
\text { Weighted mean } 96.75 \%, \\
\text { median } 98.35 \%, 95 \% \text { CI: } \\
90.87 \%, 100 \%\end{array}$ & & $\begin{array}{c}\text { Estimated cumulative } \\
\text { MBL at } 5 \text { years }(\%) \\
\text { Weighted mean } 1.40 \mathrm{~mm} \text {, } \\
\text { median } 1.24 \mathrm{~mm}, 95 \% \mathrm{CI} \text { : } \\
\quad 0.55 \mathrm{~mm}, 2.03 \mathrm{~mm}\end{array}$ & \\
\hline
\end{tabular}

TABLE 7: Life table analysis.

\begin{tabular}{lccccc}
\hline Interval (months) & Implants at risk & Failed implants & Dropouts/lost to follow-up & Implant survival rate & Cumulative survival rate \\
\hline $0-6$ & 885 & 17 & 19 & $98.08 \%$ & $98.08 \%$ \\
$6-12$ & 849 & 3 & 182 & $99.65 \%$ & $97.73 \%$ \\
$12-24$ & 664 & 1 & 140 & $99.85 \%$ & $97.59 \%$ \\
$24-36$ & 523 & 0 & 156 & $100.00 \%$ & $97.59 \%$ \\
$36-48$ & 367 & 1 & 87 & $99.73 \%$ & $97.32 \%$ \\
$48-60$ & 279 & 1 & 99 & $99.64 \%$ & $96.97 \%$ \\
$60-72$ & 179 & 1 & $10-$ & $99.44 \%$ & $96.43 \%$ \\
$72-84$ & 168 & 1 & 0 & $99.40 \%$ & $95.85 \%$ \\
$84-96$ & 167 & 0 & 6 & $100.00 \%$ & $95.85 \%$ \\
$96-108$ & 161 & 0 & 125 & $100.00 \%$ & $95.85 \%$ \\
$108-120$ & 36 & 0 & 36 & $100.00 \%$ & $95.85 \%$ \\
\hline
\end{tabular}

implants with Equator attachments. However, there was a significant difference in marginal bone loss and patient satisfaction between those receiving minidental implants with Equator attachments and conventional dental implants with ball attachments.

In the Jawad study, forty-six patients were randomly allocated to receive either two mini-implants or two conventional implants in the mandible to retain their lower dentures, and no statistical differences were found.

The majority of investigated studies reported narrow implant survival rates $>95 \%$, and only one study reported survival rates of $83.3 \%$ after 1 year. The weighted average of the estimated survival rate at five years, for removable restorations, was $96.75 \%$.

The highest incidence of failure was found in the Marcello-Machado et al. study [37]. A total of 30 patients with 60 implants suffered from 10 implant losses in 10 different patients during the healing phase. The lost implants (2.9 $\mathrm{mm}$ in diameter) were replaced by a $3.5 \mathrm{~mm}$ diameter implant. The short follow-up of the study is one of the limits of the paper, and the 5 years of estimated survival leads to an
$81.7 \%$ survival. Another study with a high failure rate was the only study describing upper jaw rehabilitations [33]. The cumulative survival rate was calculated to be $84.7 \%$ at ten years. This finding seems different if compared to those reported in the literature for standard-diameter implants. A study conducted by Fisher showed an implant survival rate of $95 \%$ at five years in edentulous patients rehabilitated with upper fixed prosthesis supported by 5-6 standard-diameter implants. As shown in Kern's review, the estimated 5-year survival rates of regular-diameter implants were $97.9 \%$ (95\% CI 97.4; 98.4) in the maxilla and 98.9\% (95\% CI 98.7; 99.1) in the mandible. The reliability of the use of NDI in completely edentulous patients is given also by the fact that there are studies with 10 years of follow-up, although with a limited number of implants.

One of the issues of the use of NDI is the fracture rate. Although described in literature, no included studies have reported such an occurrence.

Implant diameter is related to the risk of implant fracture, with reduced diameter associated with reduced mechanical stability and increased risk of overload [31]. 


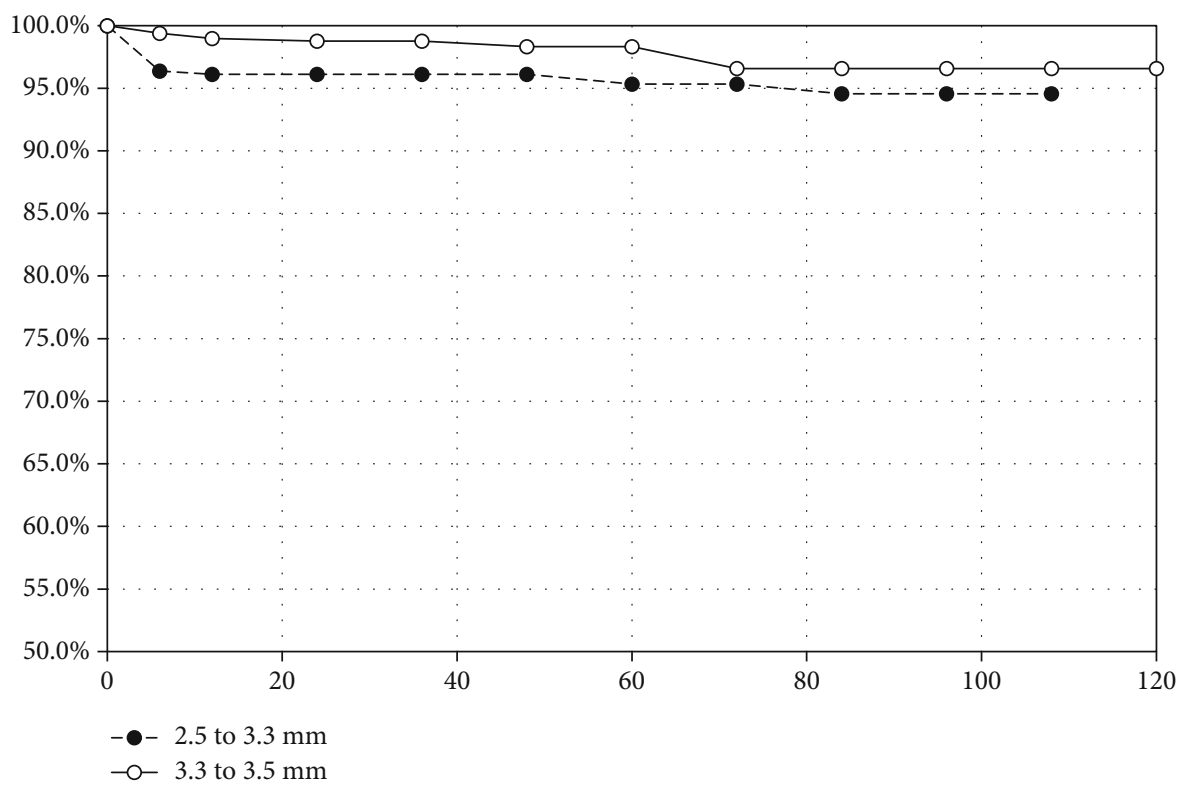

Figure 2: Kaplan-Meier analysis divided by implant diameter range.

Narrow-diameter implants have been suggested to have less resistance to mechanical forces, when compared to standard-diameter fixtures, and may increase stress transmitted to the bone.

On the other hand, El-Sheikh et al. [31] and Morneburg [34] reported no implant fractures during 6 years and 2 years of follow-ups, respectively.

According to Morneburg's study, implant fracture was avoided thanks to proper loading protocol, placement of implants in the anterior mandible, and the use of short attachments [34].

Another issue is the prosthodontic success and complication rate. Ma et al. reported the 10 -year complication rate to be very high, with only $35 \%$ of patients not needing any adjustment over time. By contrast, the patients treated in Ma et al.'s study were rehabilitated with acrylic resin without any metal framework reinforcement showing a very low number of overdenture fractures [33].

Although the data show a high survival rate, it is important to consider also the implant's success rate, health of soft tissues, and changes in the marginal bone level. Only three studies reported the implant success rate with a range from $51.3 \%$ to $94 \%$. Studies did not present well-defined success criteria. Because of limited data, it was not possible to analyze the success rate.

The average MBL value after five years was $1.40 \mathrm{~mm}$ similar to those reported for standard implants in several articles. Müller et al. [35] measured a bone level change of $0.60 \mathrm{~mm}$ confirming the favorable results of Ti-Zr ND implants. Romeo et al. compared Straumann tissue-level implants with a reduced diameter $(3.3 \mathrm{~mm})$ with standard-diameter implants $(4.1 \mathrm{~mm})$ in partially edentulous patients and found no statistically significant difference in the MBL [12]. Moreover, there was only one study comparing narrow-diameter implants with standard dental implants (Aunmeungtong) for complete den- tures, proving that the marginal bone resorption in standard implants was significantly higher than in narrow implants.

Several studies compared restorations with different numbers of narrow implants. All studies have reported the use of 2 NDI retaining a mandibular overdenture. Two studies have also included the use of 3 or 4 implants. All studies have reported the use of unsplinted implants while one reported also about a bar on 4 implants. Ball attachments are related to a decreased marginal bone loss after 3 years of follow-up regardless of implant diameter, due to a better stress distribution under peri-implant conditions when compared to the rigid connection of locator attachments.

El-Sheikh et al. [31] concluded that there were no significant differences among the considered clinical or radiographic parameters of the peri-implant tissues between two-implant overdenture versus three-implant overdenture.

As shown by Aunmeungtong et al. [30], two NDIs can be used for mandibular overdentures without any significant difference regarding marginal bone level changes and prosthodontic complications when compared to four-NDIretained overdentures.

No study was reported on fixed restoration supported by NDI.

Only two studies assessed patients' satisfaction with the overdenture by validated questionnaires based on a visual analog scale (VAS) at one year and 6 months, respectively [30, 32].

In both studies, the overall patient satisfaction with the overdenture was high (score $>60)$. The results of the questionnaire in Morneburg's study confirm that stabilization of mandibular dentures with reduced-diameter implants leads to considerable improvement of the function of the prosthesis and increased comfort for the patient.

Clinical data, from this systematic review, suggest that NDIs of $2.5 \mathrm{~mm}$ to $3.3 \mathrm{~mm}$ of diameter represent an alternative treatment option in the rehabilitation of a completely 
edentulous jaw with limited width. This could be considered a possible alternative to bone augmentation, when needed. In a recent study by Papadimitriou et al., the rehabilitation of edentulous patients using NDIs showed to require significantly less bone regeneration. At the moment, there are no studies that compare narrow-diameter implant versus standard diameter with bone augmentation procedures in fully edentulous patients.

\section{Conclusions}

In conclusion, narrow-diameter dental implants show high survival (>95\%) and acceptable, marginal bone level changes $(<1.5 \mathrm{~mm})$. Although the selected papers are difficult to compare, the results consider NDI a reliable treatment when used to retain an overdenture in the rehabilitation of edentulous jaw with survival rates and biomechanical features similar to standard-diameter implants.

It is possible to consider two-/three-implant overdentures in the mandible as a viable treatment option for edentulous patients with high survival rates.

No studies were found concerning rehabilitation fixed restorations in both mandible and maxilla. Only one study reported edentulous maxilla restored with overdentures supported by NDI.

Future RCTs should investigate the rehabilitation of edentulous patients with narrow implants vs. standarddiameter implants, as well as fixed restorations for edentulous patients.

\section{Conflicts of Interest}

The authors declare no conflict of interest.

\section{References}

[1] R. Adell, U. Lekholm, B. Rockler, and P. I. Branemark, “A 15year study of osseointegrated implants in the treatment of the edentulous jaw," International Journal of Oral Surgery, vol. 10, no. 6, pp. 387-416, 1981.

[2] D. H. Enlow, H. J. Bianco, and S. Eklund, "The remodeling of the edentulous mandible," The Journal of Prosthetic Dentistry, vol. 36, no. 6, pp. 685-693, 1976.

[3] L. Schropp, A. Wenzel, L. Kostopoulos, and T. Karring, "Bone healing and soft tissue contour changes following single-tooth extraction: a clinical and radiographic 12-month prospective study," The International Journal of Periodontics \& Restorative Dentistry, vol. 23, no. 4, pp. 313-323, 2003.

[4] M. G. Araujo and J. Lindhe, "Dimensional ridge alterations following tooth extraction. An experimental study in the dog," Journal of Clinical Periodontology, vol. 32, no. 2, pp. 212-218, 2005.

[5] W. L. Tan, T. L. Wong, M. C. Wong, and N. P. Lang, "A systematic review of post-extractional alveolar hard and soft tissue dimensional changes in humans," Clinical Oral Implants Research, vol. 23, Supplement 5, pp. 1-21, 2012.

[6] O. P. Singh, R. Kaur, S. M. Nanda, and E. Sethi, "Residual ridge resorption: a major oral disease entity in relation to bone density," Indian J Oral Sci, vol. 7, no. 1, pp. 3-6, 2016.
[7] J. Piterokovski, J. Harfin, and F. Levy, "The influence of age and denture wear on the size of edentulous structures," The Journal of Prosthetic Dentistry, vol. 20, no. 2, pp. 100-105, 1967.

[8] E. Proteasa, M. Melescanu-Imre, C. T. Preoteasa, M. Marin, and H. Lerner, "Aspects of oral morphology as decision factors in mini-implant supported overdenture," Romanian Journal of Morphology and Embryology, vol. 51, pp. 309-314, 2010.

[9] J. S. Feine, G. E. Carlsson, and M. A. Awad, "The McGill consensus statement on overdentures. Mandibular two-implant overdentures as $\mathrm{f}$ irst choice standard of care for edentulous patients," Gerodontology, vol. 19, pp. 3-4, 2002.

[10] J. M. Thomason, J. Feine, C. Exley et al., "Mandibular two implant-supported overdentures as the first choice standard of care for edentulous patients - the York Consensus Statement," British Dental Journal, vol. 207, no. 4, pp. 185-186, 2009.

[11] M. Chiapasco, P. Casentini, M. Zaniboni, E. Corsi, and T. Anello, "Titanium zirconium alloy narrow-diameter implants (Straumann Roxolid) for the rehabilitation of horizontally deficient edentulous ridges: prospective study on 18 consecutive patients," Clinical Oral Implants Research, vol. 23, no. 10, pp. 1136-1141, 2012.

[12] E. Romeo, D. Lops, L. Amorni, M. Chiapasco, M. Ghisol, and G. Vogel, "Clinical and radiographic evaluation of smalldiameter (3.3-mm) implants followed for 1-7 years: a longitudinal study," Clinical Oral Implants Research, vol. 17, no. 2, pp. 139-148, 2006.

[13] S. H. Addicks, D. W. McNeil, C. L. Randall et al., "Dental carerelated fear and anxiety: distress tolerance as a possible mechanism," JDR Clinical and Translational Research, vol. 2, no. 3, pp. 304-311, 2017.

[14] U. Lekholm and G. A. Zarb, "Patient selection and preparation," in Tissue Integrated Prostheses: Osseointegration in Clinical Dentistry, P.-I. Brånemark, G. A. Zarb, and T. Albrektsson, Eds., pp. 199-209, Quintessence, Hanover Park, IL, 1985.

[15] T. J. McGarry, A. Nimmo, J. F. Skiba, R. H. Ahlstrom, C. R. Smith, and J. H. Koumjian, "Classification system for complete edentulism," Journal of Prosthodontics, vol. 8, no. 1, pp. 27-39, 1999.

[16] I. Kovacic, S. Persic, J. Kranjcic, N. Lesic, and A. Celebic, "Rehabilitation of an extremely resorbed edentulous mandible by short and narrow dental implants," Case Reports Dentistry, vol. 2018, Article ID 7597851, 2018.

[17] S. S. Al-Johany, M. D. Al Amri, S. Alsaeed, and B. Alalola, "Dental implant length and diameter: a proposed classification scheme," Journal of Prosthodontics, vol. 26, no. 3, pp. 252-260, 2017.

[18] H. Jiansheng, X. Dongying, W. Xianfeng, X. Baoyi, L. Qiong, and Z. Jincai, "Clinical evaluation of short and wide-diameter implants immediately placed into extraction sockets of posterior areas: a 2-year retrospective study," The Journal of Oral Implantology, vol. 38, no. 6, pp. 729-737, 2012.

[19] E. Andersen, E. Saxegaard, B. M. Knutsen, and H. R. Haanaes, "A prospective clinical study evaluating the safety and effectiveness of narrow diameter threaded implants in the anterior region of the maxilla," The International Journal of Oral \& Maxillofacial Implants, vol. 16, no. 2, pp. 217-224, 2001.

[20] B. Zinsli, T. Sagesser, E. Mericske, and R. Mericske-Stern, "Clinical evaluation of small diameter ITI implants: a prospective study," The International Journal of Oral \& Maxillofacial Implants, vol. 19, pp. 92-99, 2004. 
[21] R. E. Jung, B. Al-Nawas, M. Araujo et al., "Group 1 ITI Consensus Report: the influence of implant length and design and medications on clinical and patient-reported outcomes," Clinical Oral Implants Research, vol. 29, Supplement 16, pp. 69-77, 2018.

[22] T. M. Griffitts, C. P. Collins, and P. C. Collins, "Mini dental implants: an adjunct for retention, stability, and comfort for the edentulous patient," Oral Surgery, Oral Medicine, Oral Pathology, Oral Radiology, and Endodontics, vol. 100, no. 5, pp. e81-e84, 2005.

[23] L. D. Campelo and J. R. Camara, "Flapless implant surgery: a 10-year clinical retrospective analysis," The International Journal of Oral \& Maxillofacial Implants, vol. 17, no. 2, 2002.

[24] D. Buser and T. von Arx, "Surgical procedures in partially edentulous patients with ITI implants," Clinical Oral Implants Research, vol. 11, Supplement 1, pp. 83-100, 2000.

[25] M. Davarpanah, H. Martinez, J. F. Tecucianu, R. Celletti, and R. Lazzara, "Small-diameter implants: indications and contraindications," International Journal of Esthetic Dentistry, vol. 12, no. 4, pp. 186-194, 2000.

[26] K. Akça, M. C. Çehreli, and H. İplikçioğlu, "Evaluation of the mechanical characteristics of the implant- abutment complex of a reduced-diameter morse-taper implant. A nonlinear finite element stress analysis," Clinical Oral Implants Research, vol. 14, no. 4, pp. 444-454, 2003.

[27] S. Storelli, M. Del Fabbro, M. Scanferla, G. Palandrani, and E. Romeo, "Implant supported cantilevered fixed dental rehabilitations in partially edentulous patients: systematic review of the literature. Part I," Clinical Oral Implants Research, vol. 29, Supplement 18, pp. 253-274, 2018.

[28] B. R. Kirkwood and A. C. Sterne Jonathan, "Poison regression," in Essential Medical Statistics, John Wiley \& Sons, 2010.

[29] H. Abbas, H. Bulad, and M. M. Kabbani, "A 4 years follow-up study of immediate and delayed loading of small-diameter dental implants," International Dental \& Medical Journal of Advanced Research - VOLUME 2015, vol. 3, no. 1, pp. 1-4, 2017.

[30] W. Aunmeungtong, T. Kumchai, F. P. Strietzel, P. A. Reichart, and P. Khongkhunthian, "Comparative Clinical Study of Conventional Dental Implants and Mini Dental Implants for Mandibular Overdentures: A Randomized Clinical Trial," Clinical Implant Dentistry and Related Research, vol. 19, no. 2, pp. 328-340, 2017.

[31] A. M. El-Sheikh, O. M. Shihabuddin, and G. SMF, “A Prospective Study of Early Loaded Single Implant-Retained Mandibular Overdentures: Preliminary One-Year Results," International Journal of Dentistry, vol. 2012, Article ID 285684, 7 pages, 2012.

[32] S. Jawad, C. Barclay, W. Whittaker, M. Tickle, and T. Walsh, "A pilot randomised controlled trial evaluating mini and conventional implant retained dentures on the function and quality of life of patients with an edentulous mandible," BMC Oral Health, vol. 17, no. 1, p. 53, 2017.

[33] S. Ma, N. Waddell, M. A. Atieh, N. H. M. Alsabeeha, and A. G. T. Payne, "Maxillary three-implant overdentures opposing mandibular two-implant overdentures: 10 -year prosthodontic outcomes," International Journal of Prosthodontics, vol. 29, no. 4, pp. 327-336, 2016.

[34] T. R. Morneburg, "Success rates of microimplants in edentulous patients with residual ridge resorption," The International Journal of Oral \& Maxillofacial Implants, vol. 23, no. 2, pp. 270-276, 2008.
[35] F. Müller, B. Al-Nawas, S. Storelli et al., "Small-diameter titanium grade IV and titanium-zirconium implants in edentulous mandibles: five-year results from a double-blind, randomized controlled trial," BMC Oral Health, vol. 15, no. 1, 2015.

[36] J. Zweers, A. van Doornik, E. A. H. Hogendorf, M. Quirynen, and G. A. Van der Weijden, "Clinical and radiographic evaluation of narrow- vs. regular-diameter dental implants: a 3-year follow-up. A retro spactive study," Clinical Oral Implants Research, vol. 26, no. 2, pp. 149-156, 2015.

[37] R. M. Marcello-Machado, F. Faot, A. J. Schuster, A. Machado Bielemann, O. L. C. Júnior, and A. A. D. B. Cury, "One-year clinical outcomes of locking taper Equator attachments retaining mandibular overdentures to narrow diameter implants," Clinical Implant Dentistry and Related Research, vol. 20, no. 4, pp. 483-492, 2018. 